\title{
What's Old is New Again: An Introduction to the Journal's Editorial Staff
}

\author{
Cheri J. Shapiro ${ }^{1}$ Anne F. Farrell ${ }^{2}$
}

Published online: 28 December 2019

(c) Springer Science+Business Media, LLC, part of Springer Nature 2020

What is old is new again. In March 1992, Dr. Nirbhay N. Singh, founder and inaugural editor of the Journal of Child and Family Studies, established the journal as a "single-source periodical that focuses on research, practice, evaluation, and policy issues dealing with children and adolescents, as well as their families" (Singh 1992, pp. 1). The initial call for the journal noted a changing world and called for a scholarly response to a range of challenges: "Among other factors, the worsening world and local economies, decline in literacy, increase in homelessness, breakup of the nuclear family, greater awareness as well as intolerance of gender and racial differences, continuing cutbacks in social services, and cultural bigotry have all contributed to the increasing mental health problems of children and their families" (Singh 1992, pp. 1). Nearly three decades later, these truths remain. Perhaps Dr. Singh was prescient in foreseeing the era of accountability as well as the need for a journal focused on the interactive nature of complex systems affecting families and children. Today, the Journal of Child and Family Studies remains committed to publishing high quality research that informs positive change at the child, family, neighborhood, community, and socio-political levels of the ecology. We owe the field-and our children-no less.

Since its inception, the Journal of Child and Family Studies has published 174 issues and 3221 articles broadly pertaining to the behavioral health and well-being of children, adolescents, and their families. Under the previous editorial team, led by Dr. Singh, the journal became one of the most prolific and influential outlets for scholarship in the areas of lifespan and lifecourse studies and developmental

Anne F. Farrell

afarrell@chapinhall.org

1 Institute for Families in Society, College of Social Work, University of South Carolina, Columbia, SC, USA

2 Chapin Hall at the University of Chicago, Chicago, IL, USA and educational psychology. The journal has evidenced an upward trajectory on measures of scholarly impact. We thank Dr. Singh for his vision, his excellent stewardship of this journal for so many years, and his generous support throughout this editorial transition.

Our editorial team began receiving and acting on new manuscripts as of August, 2019, a year in which the journal received close to 1200 new article submissions. Managing the journal is a significant operation, made possible only due to the service of many outstanding individuals. We are very fortunate to continue to work with a team of associate editors whose substantive and methodological expertise lends rigor to the peer review process. Associate editors play a critical role in the review procedure by shepherding manuscripts through the peer review process, summarizing the key points in the reviews, and making an initial determination on a manuscript's status. In order to be successful, associate editors rely on the service of hundreds of ad hoc reviewers who play an integral role in our ability to publish high-quality research. Reviewers provide a highly valued service by completing informed and constructive critiques of submitted manuscripts. As we move forward, our editorial team will continue to rely on the service of these dedicated individuals and look to the editorial board for guidance as we shape the future of the Journal of Child and Family Studies.

In this Editorial, we would like to share with you (1) the journal's revised aims and scope, (2) a brief introduction to the new editorial team, (3) and an invitation to contribute to the continued success of the journal.

\section{Journal of Child and Family Studies: Aims and Scope}

In line with Dr. Singh's original aim to respond to the information needs of "researchers, clinicians, and case managers, administrators, advocates, and policy makers" (Singh 1992, pp. 1) the journal's revised aims and scope 
continue to emphasize applied and translational research that informs policy and practice for children, youth, and their families. To do so, we must work across disciplines to promote and disseminate solid, practical, meaningful scientific contributions. Given these goals, the journal will continue to publish a variety of manuscript types, including full-length scholarly papers, systematic or scoping reviews, brief reports of empirical research, and commentaries. However, for the time being, we have decided to no longer publish book reviews. We look forward to special sections of the journal that bring together five or more papers organized thematically to inform an issue, challenge, or set of questions and provide an opening for scholarly discourse, commentary, and debate. We encourage authors to state in their manuscripts the practical, policy, and programmatic implications of their work, and to be clear and specific in doing so.

Aims and Scope Journal of Child and Family Studies (JCFS) is an international, peer-reviewed forum for topical issues pertaining to the behavioral health and well-being of children, adolescents, and their families. Interdisciplinary and ecological in approach, the journal focuses on individual, family, and community contexts that influence child, youth, and family well-being and translates research results into practical applications for providers, program implementers, and policymakers. Original papers address applied and translational research, program evaluation, service delivery, and policy matters that affect child, youth, and family well-being. Topic areas include but are not limited to: enhancing child, youth/young adult, parent, caregiver, and/or family functioning; prevention and intervention related to social, emotional, or behavioral functioning in children, youth, and families; cumulative effects of risk and protective factors on behavioral health, development, and well-being; the effects both of exposure to adverse childhood events and assets/protective factors; child abuse and neglect, housing instability and homelessness, and related ecological factors influencing child and family outcomes.

Given the transnational focus of the journal and the multidetermined nature of child and family development, JCFS invites papers with a range of approaches and methodologies arising from varied data sources and geographies. In addition to full length scholarly papers, the journal publishes systematic or scoping reviews, brief reports of empirical research, and commentaries.

- Serves as a prominent international forum for topical issues pertaining to the behavioral health and well-being of children, youth, and families.

- Focuses on individual, family, and community contexts that influence child, youth, and family functioning and well-being, with an emphasis on applied and translational research that informs policy and practice.

- Translates the latest research results into practical applications for providers, program implementers, and policy makers.

\section{Introduction to the Editorial Team}

Anne F. Farrell, Ph.D. I could not pass on the opportunity to serve as Co-Editor-in-Chief with Dr. Shapiro and to help shape the field's understanding of complex issues affecting children, youth, and families in partnership with an esteemed fellow translational scholar. My career is characterized by an abiding desire to bring forth new knowledge that can be readily and reliably applied to help individuals who experience adversity, so often due to factors out of their control. I believe deeply in the capacity of humans and communities to change and grow and understand those processes as most effective when their own assets are engaged in change processes. I started my career doing frontline work in the fields of child welfare and disabilities and concluded that, all too often, providers were in the position of placing new demands on families at moments of significant crisis. I hope that in some small way my own work moves to shift that stance. I see the work of editorship as a new opportunity to do so. I particularly look forward to reviewing work that is not only translational but is also salutogenic, that is, focused on factors that promote wellbeing. I have worked within and across a range of applied settings (child welfare, health and behavioral health, disabilities, education and higher education, early childhood, community organizations, out-of-school time, research, and public health). As such, I have experienced and continue to witness the challenges of delivering evidence-based interventions and knowing which might work for a particular person at a specific moment in time. I hope that, under our leadership, the Journal of Child and Family Studies can advance our collective capacity to inform change.

I offer my deepest gratitude to Nirbay Singh for ample contributions at the helm of this journal and for his gentle guidance and consistent presence in the transition period. $\mathrm{He}$ and our Springer colleagues offer their significant expertise and no small amount of faith as we embark on this journey. Having served as reviewer and editorial board member for several journals, I benefit as well from the wisdom of other colleagues under whose leadership and mentoring I have learned (am learning) to engage as editor in ways that are productive, constructive, and respectful, while always aiming to make the work better. Thanks as well to so many families and colleagues for your feedback along the way. You have helped me be a better clinician, 
scholar, thinker, and person; and to my son Patrick Spauster who pushes me at every level to be the best I can.

Cheri J. Shapiro, Ph.D. As Editor-in-Chief, I bring to my role an accumulation of nearly three decades in service to promoting the mental health and well-being of children, youth, and families. From my early doctoral training at the University of Arizona (Clinical Psychology) and an internship in Minneapolis, Minnesota, it became apparent that many families were not getting the mental health support that they needed, and, that mental health services that were typically provided at the community level were not based on empirical evidence. My path to learn, deliver, and later research implementation and dissemination of evidence-based interventions grew from this discomfiture. Over time, professional work in a wide range of service systems and settings including rural health, mental health, juvenile justice, and universities has taught me three things. First, significant barriers remain to practical use of strong scientific knowledge and evidence-based approaches to intervention. Second, no single profession or discipline has "the" answers. A transdisciplinary approach is necessary if we hope to produce and disseminate research that has clear practical implications. Third, patience is not always a virtue. We do not have time to wait while children suffer. Thus, I bring to the Journal of Child and Family Studies a sense of urgency and a deep commitment to promoting high quality research that matters to families, professionals, communities, policymakers, and fellow researchers.

I must thank Nirbay Singh directly for his mentorship from an early submission many moons ago, to support in my role as an Associate Editor. I thank him most of all for his trust in allowing me to care for this journal. The list of people I want to thank is long and several stand out: Dr. Jon McCaine for his mentorship; my mother, Dr. Ellen Marmer, and my late father, Dr. Harold Shapiro for their undying commitment to healing children, youth, and their families; and my daughters, Sarah and Bethany Smith, for their passionate desire to make the world a better place.

$A$ word on co-editorship. We chose to enter into our editorial roles in partnership, in part because of the opportunity to share the burdens of a high volume journal. More importantly, we chose to share the role because we both believe that collaboration holds the potential to sharpen our best assets and round out the less developed ones. Finally, a word of thanks to Stephen Gavazzi for introducing us to each other and for his unflagging support.

Cara Karter. It is a privilege and honor to be serving as Editorial Manager for the Journal of Child and Family Studies under the direction of Drs. Farrell and Shapiro. I am grateful for this unparalleled opportunity to immerse myself in the publication process as a young and emerging scholar. I am deeply committed to the use of research as a vehicle to amplify the voices and perspectives of individuals typically underrepresented in decision-making. As such, I am excited to support the journal's aim to apply and translate research to inform policy and practice. In my role, I will assist the Co-Editors-in-Chief with a range of tasks toward the maintenance of the journal. I am particularly eager to support guest editors with the creation of special sections that draw attention to important topics of interest to the field.

Springer Journals. We are extremely fortunate to benefit from the committed expertise of the Springer team, led by Senior Editor Jennifer Hadley, and supported by Editorial Assistant Paola Yuli, Assistant Manager of Production Vatsala Raj, and Journal Editorial Office Assistant Sherine Joseph.

\section{Invitation}

In closing this inaugural editorial, we want to thank Dr. Singh for establishing the Journal of Child and Family Studies, and providing this important outlet for the field. Our editorial team will continue to build on the successful groundwork Dr. Singh established, and acknowledge that we can only succeed with your help. As such, we are issuing invitations. We invite authors to continue to contribute to the journal's success by submitting innovative and rigorous research across a broad range of areas. We invite scholars from a range of disciplines and areas of expertise related to the journal's aims and mission to register and serve as reviewers for the journal. Finally, we invite individuals interested in further supporting the aims of the journal to consider serving as associate editors and directly influencing the rigor and integrity of manuscripts published. Please join us as we continue to build on the success of the Journal of Child and Family Studies. It will take all of us to ensure the journal continues to thrive and impact the field for many years to come.

Anne F. Farrell

Chicago, IL

Cheri J. Shapiro

Columbia, SC

\section{Reference}

Singh, N. (1992). Introductory Statement [Editorial]. Journal of Child and Family Studies, 1(1), 1-2. 